\title{
By recognizing the broader landscape, we may better anticipate the outcome of local processes: editorial comment on the feature article by Miguel Matias
}

\author{
Sean D. Connell
}

Received: 18 December 2012/ Accepted: 20 December 2012/Published online: 23 January 2013

(C) Springer-Verlag Berlin Heidelberg 2013

Patches of habitat are seldom isolated from each other because species disperse. To account for the dynamics of varying species compositions, the original view of habitats as mosaics of islands (i.e. theory of island biogeography; MacArthur and Wilson 1967) developed into models of patch dynamics (Pickett and White 1985) and metapopulation dynamics (e.g. Fahrig and Merriam 1994). This work has produced one of the most widely held generalities in ecology; the positive relationship between species diversity and size of habitat and reducing distances between like patches.

It is rather curious, however, that little attention has assessed whether surrounding habitats can mediate such within-patch and among-patch dynamics. Nearly 70 years ago, it was recognized that "each patch in this space-time mosaic is dependent on its neighbours and develops under conditions partly imposed on them" (Watt 1947). Only recently has the importance of the surrounding matrix been recognized in modern studies (Taylor et al. 1993). Certainly, in my kelp forest system, I have been struck by moderating effects of the matrix on proximity between patches (Goodsell and Connell 2008) and how proximity mediates the effect of increasing habitat (Goodsell and Connell 2002).

For these reasons, I found the study by Matias (2013) to be heightened reminder of the importance of the matrix. Matias (2013) experimentally demonstrated that the

Communicated by U. Sommer.

S. D. Connell $(\square)$

Southern Seas Ecology Laboratories, The School of Earth and Environmental Sciences, The University of Adelaide, Adelaide, SA 5001, Australia

e-mail: sean.connell@adelaide.edu.au response of animals to habitat characteristics was dependent on the surrounding matrix. The responses of assemblages of benthic macro-invertebrates to manipulations of topographic complexity were mediated by the surrounding habitat; submerged in rock pools or emerged rock. In his account for these results, he points to value in future assessments that allow us to understand how the matrix modifies the physical environment and biological resources as well as the interplay between such local-scale drivers and the regional pool of species in surrounding habitats. Indeed, by recognizing the broader landscape and regional properties, we may be in a better position to anticipate the outcome of local processes within the patches of habitats we study.

\section{References}

Fahrig L, Merriam G (1994) Conservation of fragmented populations. Conserv Biol 36:50-59

Goodsell PJ, Connell SD (2002) Can habitat loss be treated independently of habitat configuration? Implications for rare and common taxa in fragmented landscapes. Mar Ecol Prog Ser 239:37-44

Goodsell PJ, Connell SD (2008) Complexity in the relationship between matrix composition and inter-patch distance in fragmented habitats. Mar Biol 154:117-125

MacArthur R, Wilson E (1967) The theory of island biogeography. Princeton University Press, Princeton

Matias M (2013) Macrofaunal responses to structural complexity are mediated by environmental variability and surrounding habitats. Mar Biol. doi:10.1007/s00227-012-2155-7

Pickett STA, White PS (1985) The ecology of natural disturbances and patch dynamics. Academic Press, New York

Taylor PD, Fahrig L, Henein K, Merriam G (1993) Connectivity is a vital element of landscape structure. Oikos 68:571-573

Watt AS (1947) Pattern and process in the plant community. J Ecol $35: 1-22$ 